\title{
Mammalian CD1 and MR1 genes
}

\author{
Peter Reinink $^{1,2}$ • Ildiko Van Rhijn ${ }^{1,2}$
}

Received: 15 April 2016 / Accepted: 22 June 2016 / Published online: 28 July 2016

(C) The Author(s) 2016. This article is published with open access at Springerlink.com

\begin{abstract}
All higher vertebrates share the fundamental components of the adaptive immune system: the B cell receptor, the $\mathrm{T}$ cell receptor, and classical MHC proteins. At a more detailed level, their immune systems vary considerably, especially with respect to the non-polymorphic MHC class I-like proteins. In mammals, the CD1 family of lipid-presenting proteins is encoded by clusters of genes of widely divergent sizes and compositions. Another MHC class I-like protein, MR1, is typically encoded by a single gene that is highly conserved among species. Based on mammalian genomes and the available data on cellular expression profiles and protein structure, we review MR1 genes and families of CD1 genes in modern mammals from a genetic and functional perspective. Understanding the CD1 and MR1 systems across animal species provides insights into the specialized functions of the five types of CD1 proteins and facilitates careful consideration of animal models for human diseases in which immune responses to lipids and bacterial metabolites play a role.
\end{abstract}

Keywords CD1 $\cdot$ Lipid antigens $\cdot$ Mammals $\cdot$ MR1

This article is published in the Special Issue CD1, MR1, NKT, and MAIT: Evolution and Origins of Non-peptidic Antigen Recognition by $T$ lymphocytes with Guest Editor Dr. Dirk Zajonc

Ildiko Van Rhijn

i.vanrhijn@uu.nl

1 Division of Rheumatology, Immunology and Allergy, Brigham and Women's Hospital, Harvard Medical School, Boston, MA, USA

2 Department of Infectious Diseases and Immunology, Faculty of Veterinary Medicine, Utrecht University, Utrecht, The Netherlands
Whereas MHC genes and the genes for T cell receptors appeared simultaneously during evolution and are present in all extant jawed vertebrates, the genes for CD1 and MR1 have a more limited distribution. Keeping the phylogenetic relationships among animal species in mind, we will describe the CD1 and MR1 genes in extant species. The evolution of these genes is beyond the scope of this review. CD1 and MR1 proteins bind lipids and vitamin B metabolites respectively, and present these to $\mathrm{T}$ cells, as opposed to the classical MHC proteins, which present peptide antigens to T cells. CD1 and MR1 genes have not been found in fish, while fish do contain MHC class I and II genes (Dascher 2007). Reptiles (Yang et al. 2015), birds (Miller et al. 2005; Salomonsen et al. 2005), and marsupials (Baker and Miller 2007; Cheng and Belov 2014) have $\mathrm{CD} 1$ genes that can clearly be distinguished from classical MHC genes and form an interspecies group with the mammalian $\mathrm{CD} 1$ genes. CD1a, CD1b, CD1c, CD1d, and CD1e proteins most likely arose in a common ancestor of placental mammals from a primordial form of CD1. Gene duplications, deletions, and gene inactivations shaped the composition of the CD1 family of genes, possibly under selective pressure associated with an immune function. MR1 genes are absent in fish and reptiles, but in marsupials and mammals, there is typically a single functional MR1 gene. Of all the MHC Class I-like proteins, MR1 shows the highest conservation among species.

\section{Chromosomal location and gene structure of CD1 and MR1}

In mammals, the CD1 and MR1 genes are not part of the MHC locus. In humans, the CD1 and MR1 genes are located on chromosome 1 and the MHC locus lies on chromosome 6 . However, in chicken, the CD1 and MHC loci are linked (Miller et al. 2005; Salomonsen et al. 2005). The genes that 
encode the classical MHC molecules are highly polymorphic with hundreds to thousands allelic variants, and this is thought to be closely related to their function of presenting peptides to $\mathrm{T}$ cells. No allelic variants for CD1b, CD1c, and MR1 are known. Allelic variants in the form of non-synonymous single nucleotide polymorphisms in human CD1a and CD1d are known, but the affected amino acids are not located in the antigen-binding cleft or the TCR-binding surface (Han et al. 1999; Oteo et al. 2001). Together, this justifies the common description of CD1 and MR1 genes as non-polymorphic.

Because of its non-polymorphic nature, shared structural features, and the fact that it presents small metabolite antigens rather than peptides, MR1 is often compared to CD1. However, MR1 genes are distinct from CD1 genes, and, based on sequence alignments, form their own interspecies group. Even though in humans MR1 and CD1 are located in the same MHC paralogous region on chromosome 1, the MR1 locus is separate from the CD1 cluster of genes, or CD1 locus (Hashimoto et al. 1995; Shiina et al. 2001). The CD1 locus is located between the KIRREL and olfactory receptor genes and consists of multiple genes, often in both orientations. The MR1 gene is embedded between STX6 and IER5 genes. In mice, a chromosomal rearrangement caused the separation of the CD1 and MR1 genes, which are located on chromosome 3 and chromosome 1, respectively (Dascher and Brenner 2003). In the available assembled primate data, MR1 and CD1 are located on the same chromosome, but in other mammals that were studied, like cow and pig, they are not (Goldfinch et al. 2010; Reinink and Van Rhijn 2016).

The human genome encodes one MR1 protein and five different $\mathrm{CD} 1$ proteins, called $\mathrm{CD} 1 \mathrm{a}$ through $\mathrm{CD} 1 \mathrm{e}$. These five CD1 proteins and their orthologs are called CD1 isoforms. Even though for other proteins this term is used to define RNA splice variants derived from the same gene, in the CD1 field, the word isoforms is used to indicate products of separate genes. The overall structure of CD1 and MR1 proteins resembles MHC class I molecules: a type I transmembrane protein, called the heavy chain, consisting of $\alpha 1, \alpha 2$, and $\alpha 3$ domains associated with $\beta 2$ microglobulin. CD1 and MR1 genes have an intron-exon structure comparable to MHC class I genes: they contain 6 exons that encode 5' UTR and leader signal peptide, $\alpha 1$ domain, $\alpha 2$ domain, $\alpha 3$ domain, transmembrane domain, and cytoplasmic tail and 3' UTR combined (Yamaguchi et al. 1998). CD1 genes in mammals are named after the human CD1 isoform they group with, based on sequence comparison. Comparison, based on overall alignment of the full coding sequence or only the $\alpha 1$ and $\alpha 2$ domains that form the antigen binding cleft, gives identical results. This is caused by the fact that $\alpha 3$ domains are highly conserved among all CD1 isoforms within one species (Balk et al. 1989), and cytoplasmic domains, even though they show considerable differences among the isoforms, are very short. Thus, effectively, CD1 isoforms are grouped and named according to resemblance of the sequence encoding their antigen-binding cleft-forming $\alpha 1$ and $\alpha 2$ domains.

\section{CD1 in humans and common research, farm, and companion animals}

For nine mammalian species (human, rabbit, guinea pig, cow, pig, dog, horse, mouse, and rat), the CD1 genes have been studied extensively and, except for rabbit and guinea pig, their CD1 loci have been carefully mapped and curated. The functionality of many of these CD1 genes has been studied by cloning the transcripts from cDNA, sometimes followed by protein expression studies. Genomes from these nine mammalian species contain from one (rat (Katabami et al. 1998)) to thirteen (horse and dog (Dossa et al. 2014; Schjaerff et al. 2016)) CD1 genes. From rabbits, two CD1a, two CD1b, one $\mathrm{CD} 1 \mathrm{~d}$, and one CD1e transcripts have been identified, but this study was not set up or intended to define the complete rabbit CD1 locus (Hayes and Knight 2001). Southern blots suggested the presence of at least eight CD1 genes in the rabbit (Calabi et al. 1989). Guinea pigs have been reported to contain four functional genes for $\mathrm{CD} 1 \mathrm{~b}$, three for $\mathrm{CD} 1 \mathrm{c}$, one for CD1e gene, and at least five CD1 pseudogenes (Dascher et al. 1999). Later, one functional gene for CD1d was described (Looringh van Beeck et al. 2009), and one gene of unknown functionality for CD1a (Van Rhijn and Moody 2015). The guinea pig $\mathrm{CD} 1$ locus has not been mapped, but while the genome is being updated and assembled, even more CD1 genes have been identified in guinea pig (Reinink and Van Rhijn 2016). The first attempt to define the bovine CD1 locus was based on an early draft of the bovine genome and identified one CD1a gene, five CD1b genes, two CD1d genes, and a CD1e gene. Among these, the CD1a gene, three CD1b genes, and the CD1e were identified as functional genes (Van Rhijn et al. 2006). A later version of the genome brought the number of bovine CD1 genes to 12 (Nguyen et al. 2015). The porcine $\mathrm{CD} 1$ locus has been described based on BAC sequencing and contains six CD1 genes: two genes for CD1a, and one for each of the other isoforms (Eguchi-Ogawa et al. 2007). One of the $\mathrm{CD} 1 \mathrm{a}$ genes is a pseudogene. Twelve CD1 genes were mapped in the canine locus based on the available genome at the time, and a 13th gene was not mapped in the locus and was thought to be an allele (Looringh van Beeck et al. 2008). Subsequently, BAC sequencing placed the 13th gene in the locus, which is now known to contain nine CD1a genes, and one gene or each of the other isoforms (Schjaerff et al. 2016). Four of the canine CD1a genes are thought to be functional. The horse genome contains $18 \mathrm{CD} 1$ genes, among which five pseudogenes (Dossa et al. 2014). The functional equine CD1 genes are seven $\mathrm{CD} 1 \mathrm{a}$ genes, two $\mathrm{CD} 1 \mathrm{~b}$ genes, one $\mathrm{CD} 1 \mathrm{c}$ gene, one $\mathrm{CD} 1 \mathrm{~d}$ gene, and two CD1e genes. The mouse genome, with its small locus consisting of only two CD1d genes, has been 
shown to have undergone a rearrangement that caused the loss of the other CD1 genes (Bradbury et al. 1988; Dascher and Brenner 2003). Rats have only one CD1 gene, which encodes CD1d (Ichimiya et al. 1994).

\section{CD1 loci in less well studied mammalian genomes}

Only a very small number of CD1 loci of the total of almost 4000 extant species of placental mammals have been studied. For species other than human, rabbit, guinea pig, cow, pig, dog, horse, mouse, and rat, the study of CD1 genes is now facilitated by the availability of multiple genomes. It should be noted however that many genomes, especially from species other than primates and rodents, are not yet finalized and contain multiple gaps. Also, not all sequence materials may have been assigned to a chromosomal location yet, and artifacts like duplications may be present. Therefore, attempts to describe a CD1 locus based on genomic data available at a certain point in time may need to be adjusted later based on improved versions of the genome (Nguyen et al. 2015; Schjaerff et al. 2016). Because transcription and correct splicing of existing genes cannot reliably be predicted, mRNA- and cDNA-based sequences provide the most reliable data on functionality and the possible expression of individual CD1 proteins in vivo. However, RNA sequence-based data are unlikely to provide a complete overview of CD1 proteins in a species because expression of CD1 genes is often limited to a specific tissue and cell type. Therefore, to get an indication of the total number of CD1 genes in a species, searches using the basic local alignment search tool (BLAST) or collection of annotated genes in genomes provide more reliable information than expressed sequence tags or cDNA databases. Table 1 shows numbers of CD1 genes obtained from whole genomes of 15 mammals, including less well studied species like alpaca, dolphin, elephant, two bat species, panda, and sloth (Reinink and Van Rhijn 2016). Of note, BLASTbased searches reveal functional genes and pseudogenes. Therefore, differences between results of de novo BLAST searches, automated annotation of open reading frames, and published data with regard to the total number of CD1 genes per species are expected.

CD1 genes have undergone multiple duplications in most mammals, leading to extended multigene families. The general picture that emerges is that CD1a has undergone the most extensive multiplications and CD1e the least or none. Automated annotations of CD1 isoforms of species other than mouse or human often indicate a certain degree of uncertainty, and are sometimes annotated as "CD1a-like," for example. However, the golden standard for isoform assignment is sequence alignment of the combined $\alpha 1$ and $\alpha 2$ domains. All CD1 genes from 15 mammals that were

Table 1 CD1 and MR1 gene numbers

\begin{tabular}{|c|c|c|c|c|c|c|c|c|c|}
\hline Common name & Genome & Binomial species name & CD1a & CD1b & CD1c & CD1d & CD1e & Total CD1 & MR1 \\
\hline Alpaca & vicPac2 & Vicugna pacos & 1 & 1 & 1 & 1 & 1 & 5 & 1 \\
\hline Bonobo & panPan1 & Pan paniscus & 1 & 1 & 1 & 1 & 1 & 5 & 2 \\
\hline Chimpanzee & panTro4 & Pan troglodytes & 1 & 1 & 1 & 1 & 1 & 5 & 2 \\
\hline Dog & CanFam3 & Canis lupus & 9 & 1 & 1 & 1 & 1 & 13 & 1 \\
\hline Dolphin $^{\mathrm{a}}$ & turTru2 & Tursiops truncatus & 0 & 1 & 0 & 0 & 0 & 1 & 0 \\
\hline Elephant & loxAfr3 & Loxodonta africana & 1 & 2 & 1 & 1 & 1 & 6 & 1 \\
\hline Horse & equCab2 & Equus caballus & 9 & 2 & 2 & 1 & 2 & 16 & 1 \\
\hline Human & hg38 & Homo sapiens & 1 & 1 & 1 & 1 & 1 & 5 & 2 \\
\hline Megabat & pteVam1 & Pteropus vampyrus & 3 & 1 & 1 & 0 & 1 & 6 & 1 \\
\hline Microbat & myoLuc2 & Myotis lucifugus & 17 & 2 & 0 & 5 & 2 & 26 & 1 \\
\hline Mouse & $\mathrm{mm} 10$ & Mus musculus & 0 & 0 & 0 & 2 & 0 & 2 & 1 \\
\hline Panda & ailMel1 & Ailuropoda melanoleuca & 8 & 1 & 1 & 1 & 1 & 12 & 1 \\
\hline Pig & susScr3 & Sus scrofa & 2 & 1 & 1 & 1 & 2 & 7 & 1 \\
\hline Rabbit & oryCun 2 & Oryctolagus cuniculus & 5 & 2 & 0 & 1 & 2 & 10 & 0 \\
\hline Rhesus macaque & rheMac3 & Macaca mulatta & 2 & 1 & 1 & 1 & 1 & 6 & 2 \\
\hline Sloth $^{\mathrm{a}}$ & choHof1 & Choloepus hoffmanni & 1 & 0 & 0 & 1 & 0 & 2 & 1 \\
\hline
\end{tabular}

For each of the indicated mammalian genomes, a list of CD1 and MR1 genes as determined by BLAST-based searches was merged with a list of Ensembl-annotated CD1 and MR1 genes when available (adapted from (Reinink and Van Rhijn 2016)). Redundancies (genes with identical genomic location) were removed

${ }^{a}$ The dolphin and sloth genomes are not completely assembled and consist of relatively small contigs, which may have led to the fragmentation of CD1 or MR1 genes and subsequent failure of identification 


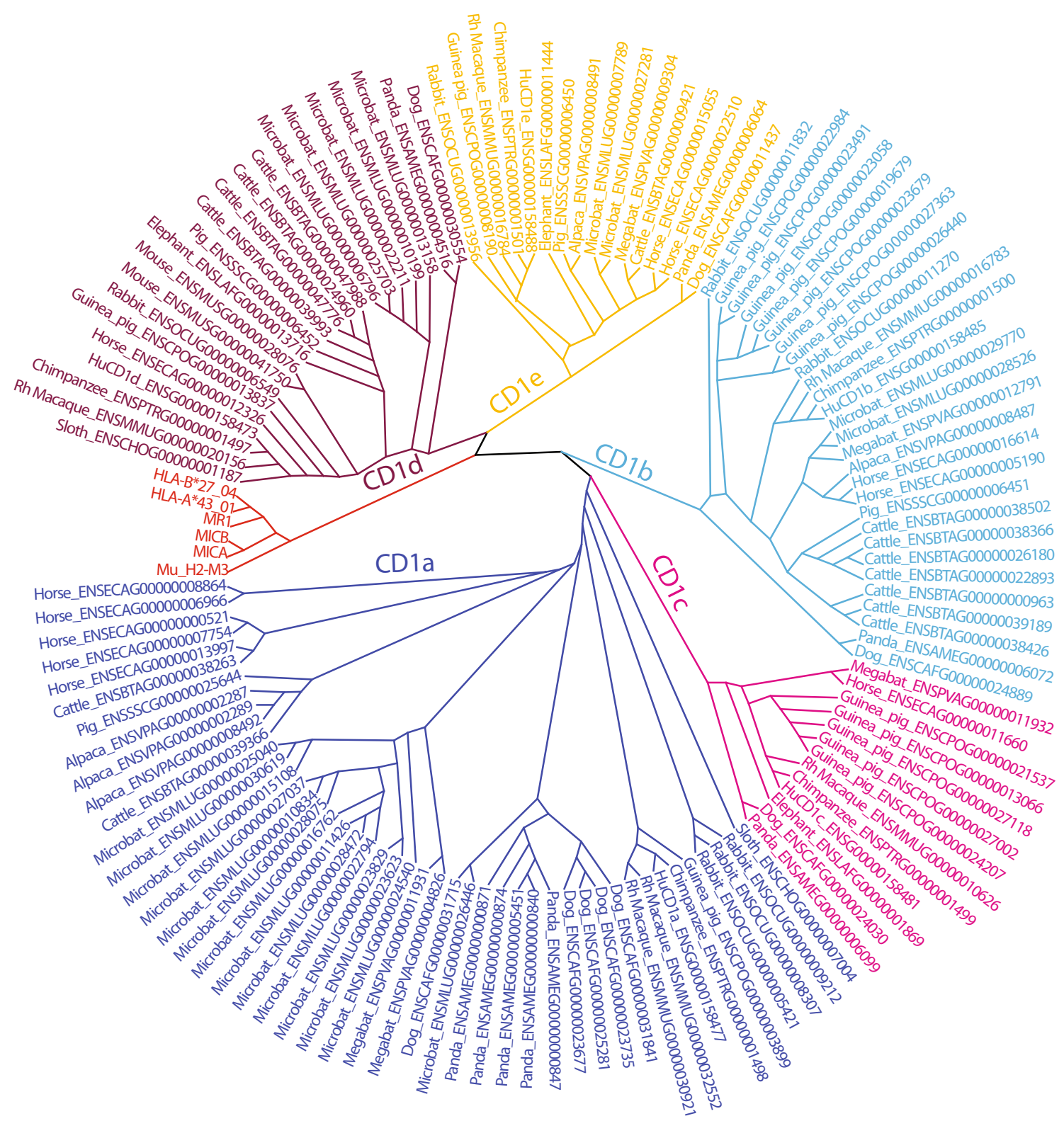

Fig. 1 CD1 and MR1 genes in mammals. From 16 mammals, known CD1 genes and predicted CD1 paralog open reading frames were obtained from Ensembl (www.ensembl.org). An alignment of these sequences and human MICA, MICB, HLA-A, HLA-B, and murine H2-

recovered group with one of the five known CD1 isoforms, but were not always correctly named by automated annotation (Fig. 1). The clear grouping with the five isoforms suggests that the isoform nomenclature that was based on the human CD1 locus appropriately describes all currently known mammalian CD1 isoforms. With more than $10 \mathrm{CD} 1$ genes, the little brown bat, Myotis lucifugus, can be considered a species with high numbers of CD1 genes. Intermediate numbers are found primates, alpaca, and elephant. These data confirm once more that mouse and rat are atypical with the lowest absolute number of CD1 genes (two and one, respectively). Though not identical, the gene
M3 was generated by MUSCLE (Edgar 2004), clustered according to a neighbor joining algorithm, and shown as a radial cladogram. Groups were color-coded based on the clustering with human CD1 isoforms

numbers obtained by BLAST-based searches and automated annotation are largely consistent (Reinink and Van Rhijn 2016). Because misassemblies of repeated sequences and unmerged overlaps due to polymorphisms resulting in artificial duplications can occur in incompletely assembled genomes, we expect that in some species, the exact numbers of CD1 genes will be adjusted in the future. However, it is clear that humans should be considered to have an intermediate number of $\mathrm{CD} 1$ genes, while many other mammals have more extensive families of CD1 genes. Large CD1 families are often dominated by multiplied CD1a genes and to a lesser degree, CD1b, CD1c, and CD1d genes. 


\section{Mammalian MR1 genes}

Searches in whole genomes (Table 1), as well as other published data, show that primates have two MR1 genes. In humans and chimpanzees, one of these genes is known to be functional and the other one is a pseudogene (Parra-Cuadrado et al. 2001; Parra-Cuadrado et al. 2000). No MR1 gene could be identified in the rabbit genome, which is in line with recently published data on lagomorphs (rabbit and pika) (Boudinot et al. 2016). The panda and dog MR1 genes that resulted from BLAST-based searches (Table 1) are most likely pseudogenes because it was shown that members of the order of Carnivora, including cats, dogs, ferrets, and pandas, have a MR1 pseudogene and lack a functional MR1 gene (Boudinot et al. 2016). Other mammals (alpaca, elephant, horse, bat) also have one MR1 gene. While in dolphin no MR1 gene was found, this does not conclusively prove the absence of MR1 in this species because the dolphin genome is still incompletely assembled. The sloth MR1 gene has a gap in the current version of the sloth genome (choHofl).

\section{Functional specialization of CD1 isoforms}

Interspecies comparisons between individual CD1 proteins have been made based on sequence alignment, protein models (canine versus human CD1a (Looringh van Beeck et al. 2008)), or crystal structures (bovine versus human CD1b (Girardi et al. 2010), bovine versus human CD1d (Wang et al. 2012), and murine versus human CD1d (Koch et al. 2005)). CD1 proteins within one species differ from each other in ways that suggest functional specialization. One aspect determines the function of a CD1 protein is the size and shape of the antigen-binding cleft, which is formed by the $\alpha 1$ and $\alpha 2$ helices. Among the human CD1 proteins, the biggest size difference is observed between CD1a and CD1b. In addition, there are significant differences in shape with the CD1b cleft consisting of four pockets (Gadola et al. 2002) of which three are interconnected and the CD1a cleft consisting of one cavity (Zajonc et al. 2003). These differences translate into differences in size and shape of antigens that can be bound by the human CD1a and CD1b proteins. Because the CD1 isoforms form interspecies groups based on phylogenetic relationship based on the sequences of their $\alpha 1$ and $\alpha 2$ helices, functional specializations of CD1 molecules that relate to the antigenbinding cleft are generally conserved across species. Especially, the size of the cleft seems to be well conserved when human $\mathrm{CD} 1$ isoforms are compared with an ortholog. However, as seen in the bovine CD1d molecule, despite a very high homology between human and bovine CD1d, tryptophan 166 in the bovine protein, which is a cysteine in humans and mice, blocks part of the A' pocket so that long fatty acyl chains will not fit (Wang et al. 2012). A comparable situation exists when human $\mathrm{CD} 1 \mathrm{~b}$ and bovine $\mathrm{CD} 1 \mathrm{~b} 3$ are compared: the tunnel that is present in the human CD1b protein is closed in bovine CD1b3 by valine 98 , which prevents the binding of extremely long ligands (Girardi et al. 2010). Structural aspects of these CD1 molecules will be reviewed by Zajonc et al. in this special issue of Immunogenetics. Thus, despite very high sequence homology and overall structural resemblance between orthologs, a single amino acid difference can have profound functional impact.

One specific feature of CD1 molecules that is difficult to predict from crude genomic data is the cytoplasmic tail, which determines the transport and subcellular location of individual CD1 isoforms (Moody and Porcelli 2003). The cytoplasmic tail is encoded by the very small exon 5 that is located between two longer introns of variable length and cannot reliably be predicted based on the genomic sequence of the CD1 gene. However, the many cDNA sequences that are available have provided a number of cytoplasmic tails that allows for comparative analysis and predictions on intracellular trafficking of these CD1 proteins (Table 2).

\section{Intracellular trafficking is determined by the CD1 cytoplasmic tail}

Cellular lipids are bound in the antigen binding cleft during synthesis of the $\mathrm{CD} 1$ protein. When the $\mathrm{CD} 1$ protein recycles and encounters other lipids in an endosomal compartment, these may replace the initial endoplasmic reticulum-derived lipid. The type of endosomal compartment a lipid travels to is thus a determining factor in the kind of antigenic lipids it presents. The cytoplasmic tails of CD1 molecules may or may not contain short consensus sequences for adaptor proteins. CD1b, CD1c, or CD1d molecules often carry a modified dileucine motif and/or a tyrosine-based YXXZ motif, where $\mathrm{X}$ is any amino acid, and $\mathrm{Z}$ is a bulky hydrophobic amino acid. YXXZ motifs interact with adaptor proteins and are responsible for recycling from the cell surface to intermediate and late endosomal compartments (Briken et al. 2002; Sugita et al. 2002). CD1e does not appear at the cell surface and does not recycle and has a function in lipid antigen loading and processing (Angenieux et al. 2005; de la Salle et al. 2005).

Comparing the cytoplasmic tails of all cell surfaceexpressed isoforms across species, the following general picture emerges: CD1a tails are highly variable in length. Most CD1a tails contain histidine residues, with unknown function, or cysteines, which can be palmitoylated. The human CD1a cytoplasmic tail contains a cysteine residue that is palmitoylated and involved in incorporation in lipid rafts (Barral et al. 2008; Sloma et al. 2008), but the mechanism of recycling to the sorting or early endosomal compartment, which is so typical for human CD1a, is unknown. None of the 17 known cytoplasmic tails of $\mathrm{CD} 1$ a proteins has a 
Table 2 Cytoplasmic tails of CD1 proteins in mammals

\begin{tabular}{|c|c|c|c|}
\hline Gene name (alias) & Cytoplasmic tail & Motif & Reference cDNA \\
\hline boCD1a2 & RKSWSTYMSDA & & (Nguyen et al. 2015) \\
\hline $\begin{array}{l}\text { boCD1a1 } \\
\text { boCD1a }\end{array}$ & WKHWTHRESPSSVLPLE & & (Van Rhijn et al. 2006) \\
\hline canCD1a2 & KAHWRPQCMDFPSEREPSSPSSSTYLNPAQH & & (Schjaerff et al. 2016) \\
\hline canCD1a6 & KRWKTHNRPQCTDFPLK & & (Looringh van Beeck et al. 2008) \\
\hline $\begin{array}{l}\text { canCD1a9 } \\
\text { canCD1a8.1 }\end{array}$ & KAHWRPQCTDFPSEQEPSSPGSSTYLNPAQH & & (Looringh van Beeck et al. 2008; Schjaerff et al. 2016) \\
\hline $\begin{array}{l}\text { canCD1a8 } \\
\text { canCD1a8.2 }\end{array}$ & KRWKAH & & (Looringh van Beeck et al. 2008; Schjaerff et al. 2016) \\
\hline eqCD1a1 & THCEAPCTIVPLK & & (Dossa et al. 2014) \\
\hline eqCD1a2 & IRHQLQRTLLPLD & Dileucine & (Dossa et al. 2014) \\
\hline eqCD1a3 & IHSELPRTLLPLE & Dileucine & (Dossa et al. 2014) \\
\hline eqCD1a4 & VISISVSILVRKPCATPRTPLPSQ & & (Dossa et al. 2014) \\
\hline eqCD1a5 & RSCESASNLLWNEIPGAQDPGHI & Dileucine & (Dossa et al. 2014) \\
\hline eqCD1a6 & WLRKRWTRCEPPSNLISLE & & (Dossa et al. 2014) \\
\hline eqCD1a7 & WLRKRGTHCEFPRTCLPLE & & (Dossa et al. 2014) \\
\hline huCD1a & RKRCFC & & (Calabi and Milstein 1986; Martin et al. 1987) \\
\hline $\begin{array}{l}\text { pigCD1a1 } \\
\text { pCD1.1 }\end{array}$ & WHRKHWKHCDPSSALHRLE & & (Chun et al. 1999; Eguchi-Ogawa et al. 2007) \\
\hline rabCD1a1 & RKCWIHHGPLETLLPLQ & Dileucine & (Hayes and Knight 2001) \\
\hline rabCD1a2 & KKRWSHHGSPNSLLPLK & Dileucine & (Hayes and Knight 2001) \\
\hline boCD1b1 & RFMGSHRVGHD & & (Nguyen et al. 2015; Van Rhijn et al. 2006) \\
\hline boCD1b3 & RRWSYQNIL & YXXZ, dileucine & (Nguyen et al. 2015; Van Rhijn et al. 2006) \\
\hline boCD1b5 & RRWSYQTIL & YXXZ, dileucine & (Nguyen et al. 2015) \\
\hline canCD1b & RRWSYQSIS & YXXZ & (Looringh van Beeck et al. 2008) \\
\hline eqCD1b1 & SYQNIS & YXXZ & (Dossa et al. 2014) \\
\hline eqCD1b2 & SYLNIP & YXXZ & (Dossa et al. 2014) \\
\hline gpCD1b1 & RRWSYEDIL & YXXZ, dileucine & (Dascher et al. 1999; Hiromatsu et al. 2002) \\
\hline gpCD1b2 & KHWSYQDIL & YXXZ, dileucine & (Dascher et al. 1999; Dascher et al. 2002) \\
\hline gpCD1b3 & RRLRCEGIF & & (Dascher et al. 1999; Dascher et al. 2002) \\
\hline gpCD1b4 & RRWSYEDIF & YXXZ & (Dascher et al. 1999) \\
\hline huCD1b & RRRSYQNIP & YXXZ & (Martin et al. 1987) \\
\hline $\begin{array}{l}\text { ovCD1b } \\
\text { scd1b42 }\end{array}$ & RRWSYQNIL & YXXZ, dileucine & (Ferguson et al. 1996) \\
\hline $\begin{array}{l}\text { ovCD1b } \\
\text { scd1b52 }\end{array}$ & RRWSHRNIL & Dileucine & (Ferguson et al. 1996) \\
\hline $\begin{array}{l}\text { ovCD1b } \\
\text { scd1a25 }\end{array}$ & RRWSYLTIL & YXXZ, dileucine & (Ferguson et al. 1996) \\
\hline pigCD1b & RRWSYQSVL & YXXZ & (Eguchi-Ogawa et al. 2007) \\
\hline $\mathrm{rabCD} 1 \mathrm{~b}$ & RRRSYQNIL & YXXZ, dileucine & (Calabi et al. 1989; Hayes and Knight 2001) \\
\hline canCD1c & RKCCSYQDIP & YXXZ & (Looringh van Beeck et al. 2008) \\
\hline eqCD1c & SYQNIQRDSSPCFPHCNENCTAQEHRTTE & YXXZ & (Dossa et al. 2014) \\
\hline gpCD1c1 & KRCTYQGIQ & YXXZ & (Dascher et al. 1999) \\
\hline gpCD1c2 & KRCTYQGIP & YXXZ & (Dascher et al. 1999) \\
\hline gpCD1c3 & KKCCTYQGIP $^{\mathrm{a}}$ & YXXZ & (Dascher et al. 1999) \\
\hline huCD1c & KKHCSYQDIL & YXXZ, dileucine & (Martin et al. 1987) \\
\hline eqCD1d & KKRSSYQDIL & YXXZ, dileucine & (Dossa et al. 2014; Looringh van Beeck et al. 2009) \\
\hline gpcD1d & RRGRSYQDIL & YXXZ, dileucine & (Looringh van Beeck et al. 2009) \\
\hline
\end{tabular}


Table 2 (continued)

\begin{tabular}{llll}
\hline Gene name (alias) & Cytoplasmic tail & Motif & Reference cDNA \\
\hline huCD1d & RFKQTSYQGVL & YXXZ, dileucine & (Balk et al. 1989) \\
lafCD1d & KRHCS & & (Looringh van Beeck et al. 2009) \\
moCD1d1 & RRRSAYQDIR & YXXZ & (Bradbury et al. 1988) \\
moCD1d2 & RRRSAYQDIR & YXXZ & (Bradbury et al. 1988) \\
ovCD1d & RKHRRYQDIS & YXXZ, dileucine & (Rhind et al. 1999) \\
scd1d & RRRVYQNIQ & YXXZ & (Eguchi-Ogawa et al. 2007) \\
pigCD1d & RRRCSYQGIL & YXXZ, dileucine & (Calabi et al. 1989; Looringh van Beeck et al. 2009) \\
rabCD1d & RRRSYQDIM & YXXZ & (Ichimiya et al. 1994) \\
ratCD1d & & &
\end{tabular}

The cytoplasmic tails of CD1 proteins, grouped by isoform. Only tail sequences that have been confirmed by cDNA sequences are included. Species from which the sequences were derived are indicated as bo: bovine; can: canine; eq: equine; gp: guinea pig; hu: human; laf: African elephant; mo: mouse; ov: ovine; rab: rabbit; dileucine: modified dileucine motif

${ }^{\text {a }}$ The sequence shown is based on GenBank sequence NM_001172855, but has been published as KKCCTYQGFP (Dascher et al. 1999)

modified dileucine- and/or a tyrosine-based YXXZ motif, consistent with the absence from intermediate and late endosomes of the human CD1 a protein, and strongly suggesting that this is an evolutionary conserved feature (Table 2 ). CD1b, CD1c, and CD1d tails are of comparable length, typically contain a YXXZ motif, and sometimes an additional modified dileucine motif. In addition, all known CD1c cytoplasmic tails contain a cysteine of unknown function. There are exceptions to these general observations, like the bovine CD1b1 (Nguyen et al. 2015), guinea pig CD1b3 (Dascher et al. 1999), and African elephant CD1d (Looringh van Beeck et al. 2009) cytoplasmic tails, which lack any known motif. Indeed, guinea pig CD1b3 does not travel to late endosomes and rather has a CD1a-like subcellular distribution pattern (Dascher et al. 2002). However, the bovine CD1b3 and CD1b5 and guinea pig CD1b1, CD1b2, and CD1b4 have "typical" CD1b cytoplasmic tails. Thus, cows and guinea pigs have typical and atypical cytoplasmic tails among the proteins belonging to the CD1b isoform. For the African elephant, no other cytoplasmic tails have been sequenced from cDNA yet. Generally speaking, it seems that when there are multiple proteins of one CD1 isoform in a species, there is functional diversification, but when a species has just one gene for a certain CD1 isoform, this one gene usually shows the "typical" combination of cleft and tail.

\section{Expression patterns of CD1 isoforms}

Human cortical thymocytes express high levels of CD1a, CD1b, CD1c, and CD1d on their cell surface. Broad CD1 expression in the thymus was confirmed in all other species where CD1 expression was studied (Hiromatsu et al. 2002; Howard et al. 1993; Looringh van Beeck et al. 2008; Van Rhijn et al. 2006). Outside the thymus, the general picture that emerges is that CD1d is widely expressed at a low level, with some specific high CD1d-expressing cells in certain tissues, like hepatic stellate cells in the liver (Winau et al. 2007), and marginal zone B cells in the spleen (Makowska et al. 1999). In humans, CD1b expression is limited to dendritic cells; CD1a is expressed by dendritic cells and at high levels by Langerhans cells in the skin, and CD1c is expressed by dendritic cells and subsets of B cells. Like humans, dogs express CD1a in the skin and thymus (Looringh van Beeck et al. 2008). However, only two of the three studied canine CD1a genes (out of the nine CD1a genes in the dog CD1 locus) were preferentially expressed in the skin. In rabbits, one of the two CD1a genes is preferentially expressed in the skin, while the other one has a more general expression pattern (Hayes and Knight 2001). In guinea pigs, different CD1b genes have different expression patterns in peripheral blood and spleen (Hiromatsu et al. 2002). Mice that are transgenic for the part of the human locus that encodes CD1a, CD1b, CD1c, and CD1e with their endogenous promoters show a CD1 expression pattern that is surprisingly comparable to the human CD1 expression pattern in that all isoforms are expressed on thymocytes and lymph node dendritic cells, while CD1a stands out as highly expressed on Langerhans cells, and CD1c is expressed on B cells (Felio et al. 2009).

\section{Closing remarks}

A typical pattern of gene distribution has been described for immune function-related genes including genes that encode TCRs, immunoglobulins, classical MHC molecules, and NK receptors. This pattern is the result of gene family expansion, diversification, and contraction or "birth and death" evolution, and usually leads to families of genes that include a considerable number of pseudogenes (Nei and Rooney 2005). Furthermore, complete loss of certain family members and 
expansion of other family members are observed when contemporary animal species are compared. With its many duplications, deletions, and pseudogenes, the CD1 loci seem to follow this pattern. Although MR1 genes have been subject to inactivation in the carnivores, extensive gene family expansion and diversification were not observed in any of the species studied. The lack of functional diversification of MR1 genes is hard to explain but may be related to its seemingly exclusive interaction with the highly specialized MAIT cells.

Even though mammals vary widely in the numbers of CD1 genes they have, some general observations can be made and help understand the function of the different $\mathrm{CD} 1$ isoforms. The skin seems to be a preferred site for CD1a expression across species. While CD1a genes have undergone extensive multiplication in some species, even more so than CD1b and CD1c, none of the currently described CD1a proteins contains any known signal for endosomal location. Multiplication and diversification of genes may have occurred in response to changes in the environment, including pathogenic and non-pathogenic microbes, to which evolving mammals were exposed.

Acknowledgments This work was supported by The Netherlands Organisation for Scientific Research (NWO) grant 824.02.002.

Open Access This article is distributed under the terms of the Creative Commons Attribution 4.0 International License (http:// creativecommons.org/licenses/by/4.0/), which permits unrestricted use, distribution, and reproduction in any medium, provided you give appropriate credit to the original author(s) and the source, provide a link to the Creative Commons license, and indicate if changes were made.

\section{References}

Angenieux C, Fraisier V, Maitre B, Racine V, van der Wel N, Fricker D, Proamer F, Sachse M, Cazenave JP, Peters P, Goud B, Hanau D, Sibarita JB, Salamero J, de la Salle H (2005) The cellular pathway of CD1e in immature and maturing dendritic cells. Traffic 6:286-302

Baker ML, Miller RD (2007) Evolution of mammalian CD1: marsupial $\mathrm{CD} 1$ is not orthologous to the eutherian isoforms and is a pseudogene in the opossum Monodelphis domestica. Immunology 121:113-121

Balk SP, Bleicher PA, Terhorst C (1989) Isolation and characterization of a cDNA and gene coding for a fourth CD1 molecule. Proc Natl Acad Sci U S A 86:252-256

Barral DC, Cavallari M, McCormick PJ, Garg S, Magee AI, Bonifacino JS, De Libero G, Brenner MB (2008) CD1a and MHC class I follow a similar endocytic recycling pathway. Traffic 9:1146-1157

Boudinot P, Mondot S, Jouneau L, Teyton L, Lefranc MP, Lantz O (2016) Restricting nonclassical MHC genes coevolve with TRAV genes used by innate-like T cells in mammals. Proc Natl Acad Sci USA 113:E2983-E2992

Bradbury A, Belt KT, Neri TM, Milstein C, Calabi F (1988) Mouse CD1 is distinct from and co-exists with TL in the same thymus. EMBO J 7:3081-3086

Briken V, Jackman RM, Dasgupta S, Hoening S, Porcelli SA (2002) Intracellular trafficking pathway of newly synthesized $\mathrm{CD} 1 \mathrm{~b}$ molecules. EMBO J 21:825-834
Calabi F, Belt KT, Yu CY, Bradbury A, Mandy WJ, Milstein C (1989) The rabbit $\mathrm{CD} 1$ and the evolutionary conservation of the $\mathrm{CD} 1$ gene family. Immunogenetics 30:370-377

Calabi F, Milstein C (1986) A novel family of human major histocompatibility complex-related genes not mapping to chromosome 6 . Nature 323:540-543

Cheng Y, Belov K (2014) Characterisation of non-classical MHC class I genes in the Tasmanian devil (Sarcophilus harrisii). Immunogenetics 66:727-735

Chun T, Wang K, Zuckermann FA, Gaskins HR (1999) Molecular cloning and characterization of a novel CD1 gene from the pig. J Immunol 162:6562-6571

Dascher CC (2007) Evolutionary biology of CD1. Curr Top Microbiol Immunol 314:3-26

Dascher CC, Brenner MB (2003) Evolutionary constraints on CD1 structure: insights from comparative genomic analysis. Trends Immunol 24:412-418

Dascher CC, Hiromatsu K, Naylor JW, Brauer PP, Brown KA, Storey JR, Behar SM, Kawasaki ES, Porcelli SA, Brenner MB, LeClair KP (1999) Conservation of a CD1 multigene family in the guinea pig. J Immunol 163:5478-5488

Dascher CC, Hiromatsu K, Xiong X, Sugita M, Buhlmann JE, Dodge IL, Lee SY, Roura-Mir C, Watts GF, Roy CJ, Behar SM, Clemens DL, Porcelli SA, Brenner MB (2002) Conservation of CD1 intracellular trafficking patterns between mammalian species. J Immunol 169: 6951-6958

de la Salle H, Mariotti S, Angenieux C, Gilleron M, Garcia-Alles LF, Malm D, Berg T, Paoletti S, Maitre B, Mourey L, Salamero J, Cazenave JP, Hanau D, Mori L, Puzo G, De Libero G (2005) Assistance of microbial glycolipid antigen processing by CD1e. Science 310:1321-1324

Dossa RG, Alperin DC, Hines MT, Hines SA (2014) The equine CD1 gene family is the largest and most diverse yet identified. Immunogenetics 66:33-42

Edgar RC (2004) MUSCLE: multiple sequence alignment with high accuracy and high throughput. Nucleic Acids Res 32:1792-1797

Eguchi-Ogawa T, Morozumi T, Tanaka M, Shinkai H, Okumura N, Suzuki K, Awata T, Uenishi H (2007) Analysis of the genomic structure of the porcine CD1 gene cluster. Genomics 89:248-261

Felio K, Nguyen H, Dascher CC, Choi HJ, Li S, Zimmer MI, Colmone A, Moody DB, Brenner MB, Wang CR (2009) CD1-restricted adaptive immune responses to mycobacteria in human group $1 \mathrm{CD} 1$ transgenic mice. J Exp Med 206:2497-2509

Ferguson ED, Dutia BM, Hein WR, Hopkins J (1996) The sheep CD1 gene family contains at least four CD1B homologues. Immunogenetics 44 : 86-96

Gadola SD, Zaccai NR, Harlos K, Shepherd D, Castro-Palomino JC, Ritter G, Schmidt RR, Jones EY, Cerundolo V (2002) Structure of human CD1b with bound ligands at 2.3A, a maze for alkyl chains. Nat Immunol 3:721-726

Girardi E, Wang J, Mac TT, Versluis C, Bhowruth V, Besra G, Heck AJ, Van Rhijn I, Zajonc DM (2010) Crystal structure of bovine CD1b3 with endogenously bound ligands. J Immunol 185:376-386

Goldfinch N, Reinink P, Connelley T, Koets A, Morrison I, Van Rhijn I (2010) Conservation of mucosal associated invariant T (MAIT) cells and the MR1 restriction element in ruminants, and abundance of MAIT cells in spleen. Vet Res 41:62

Han M, Hannick LI, DiBrino M, Robinson MA (1999) Polymorphism of human CD1 genes. Tissue Antigens 54:122-127

Hashimoto K, Hirai M, Kurosawa Y (1995) A gene outside the human MHC related to classical HLA class I genes. Science 269:693-695

Hayes SM, Knight KL (2001) Group 1 CD1 genes in rabbit. J Immunol 166:403-410

Hiromatsu K, Dascher CC, Sugita M, Gingrich-Baker C, Behar SM, LeClair KP, Brenner MB, Porcelli SA (2002) Characterization of guinea-pig group $1 \mathrm{CD} 1$ proteins. Immunology 106:159-172 
Howard CJ, Sopp P, Bembridge G, Young J, Parsons KR (1993) Comparison of CD1 monoclonal antibodies on bovine cells and tissues. Vet Immunol Immunopathol 39:77-83

Ichimiya S, Kikuchi K, Matsuura A (1994) Structural analysis of the rat homologue of CD1. Evidence for evolutionary conservation of the CD1D class and widespread transcription by rat cells. J Immunol 153:1112-1123

Katabami S, Matsuura A, Chen HZ, Imai K, Kikuchi K (1998) Structural organization of rat CD1 typifies evolutionarily conserved CD1D class genes. Immunogenetics 48:22-31

Koch M, Stronge VS, Shepherd D, Gadola SD, Mathew B, Ritter G, Fersht AR, Besra GS, Schmidt RR, Jones EY, Cerundolo V (2005) The crystal structure of human CD1d with and without alphagalactosylceramide. Nat Immunol 6:819-826

Looringh van Beeck FA, Reinink P, Hermsen R, Zajonc DM, Laven MJ, Fun A, Troskie M, Schoemaker NJ, Morar D, Lenstra JA, Vervelde L, Rutten VP, van Eden W, Van Rhijn I (2009) Functional CD1d and/or NKT cell invariant chain transcript in horse, pig, African elephant and guinea pig, but not in ruminants. Mol Immunol 46:1424-1431

Looringh van Beeck FA, Zajonc DM, Moore PF, Schlotter YM, Broere F, Rutten VP, Willemse T, Van Rhijn I (2008) Two canine CD1a proteins are differentially expressed in skin. Immunogenetics 60:315-324

Makowska A, Faizunnessa NN, Anderson P, Midtvedt T, Cardell S (1999) CD1high B cells: a population of mixed origin. Eur J Immunol 29:3285-3294

Martin LH, Calabi F, Lefebvre FA, Bilsland CA, Milstein C (1987) Structure and expression of the human thymocyte antigens CD1a, CD1b, and CD1c. Proc Natl Acad Sci U S A 84:9189-9193

Miller MM, Wang C, Parisini E, Coletta RD, Goto RM, Lee SY, Barral DC, Townes M, Roura-Mir C, Ford HL, Brenner MB, Dascher CC (2005) Characterization of two avian MHC-like genes reveals an ancient origin of the CD1 family. Proc Natl Acad Sci U S A 102:8674-8679

Moody DB, Porcelli SA (2003) Intracellular pathways of CD1 antigen presentation. Nat Rev Immunol 3:11-22

Nei M, Rooney AP (2005) Concerted and birth-and-death evolution of multigene families. Annu Rev Genet 39:121-152

Nguyen TK, Reinink P, El Messlaki C, Im JS, Ercan A, Porcelli SA, Van Rhijn I (2015) Expression patterns of bovine CD1 in vivo and assessment of the specificities of the anti-bovine CD1 antibodies. PLoS One 10:e121923

Oteo M, Arribas P, Setien F, Parra JF, Mirones I, Gomez del Moral M, Martinez-Naves E (2001) Structural characterization of two CD1A allelic variants. Hum Immunol 62:1137-1141

Parra-Cuadrado JF, Gomez del Moral M, Garcia-Pavia P, Setien F, MartinezNaves E (2001) Characterization of the MHC class I-related MR1 locus in nonhuman primates. Immunogenetics 53:643-648

Parra-Cuadrado JF, Navarro P, Mirones I, Setien F, Oteo M, MartinezNaves E (2000) A study on the polymorphism of human MHC class I-related MR1 gene and identification of an MR1-like pseudogene. Tissue Antigens 56:170-172
Reinink P, Van Rhijn I (2016) In silico method for identification of MHC class I-like molecules in whole genomes. BioRxiv. doi:10.1101/046607

Rhind SM, Hopkins J, Dutia BM (1999) Amino-terminal sequencing of sheep CD1 antigens and identification of a sheep CD1D gene. Immunogenetics 49:225-230

Salomonsen J, Sorensen MR, Marston DA, Rogers SL, Collen T, van Hateren A, Smith AL, Beal RK, Skjodt K, Kaufman J (2005) Two $\mathrm{CD} 1$ genes map to the chicken $\mathrm{MHC}$, indicating that $\mathrm{CD} 1$ genes are ancient and likely to have been present in the primordial MHC. Proc Natl Acad Sci U S A 102:8668-8673

Schjaerff M, Keller SM, Fass J, Froenicke L, Grahn RA, Lyons L, Affolter VK, Kristensen AT, Moore PF (2016) Refinement of the canine $\mathrm{CD} 1$ locus topology and investigation of antibody binding to recombinant canine CD1 isoforms. Immunogenetics 68:191-204

Shiina T, Ando A, Suto Y, Kasai F, Shigenari A, Takishima N, Kikkawa E, Iwata K, Kuwano Y, Kitamura Y, Matsuzawa Y, Sano K, Nogami M, Kawata H, Li S, Fukuzumi Y, Yamazaki M, Tashiro H, Tamiya G, Kohda A, Okumura K, Ikemura T, Soeda E, Mizuki N, Kimura M, Bahram S, Inoko H (2001) Genomic anatomy of a premier major histocompatibility complex paralogous region on chromosome 1q21-q22. Genome Res 11:789-802

Sloma I, Zilber MT, Vasselon T, Setterblad N, Cavallari M, Mori L, De Libero G, Charron D, Mooney N, Gelin C (2008) Regulation of $\mathrm{CD} 1$ a surface expression and antigen presentation by invariant chain and lipid rafts. J Immunol 180:980-987

Sugita M, Cao X, Watts GF, Rogers RA, Bonifacino JS, Brenner MB (2002) Failure of trafficking and antigen presentation by CD1 in AP3-deficient cells. Immunity 16:697-706

Van Rhijn I, Koets AP, Im JS, Piebes D, Reddington F, Besra GS, Porcelli SA, van Eden W, Rutten VP (2006) The bovine CD1 family contains group 1 CD1 proteins, but no functional CD1d. J Immunol 176:4888-4893

Van Rhijn I, Moody DB (2015) CD1 and mycobacterial lipids activate human T cells. Immunol Rev 264:138-153

Wang J, Guillaume J, Pauwels N, Van Calenbergh S, Van Rhijn I, Zajonc DM (2012) Crystal structures of bovine CD1d reveal altered aGalCer presentation and a restricted A' pocket unable to bind very long-chain lipids. PLoS One 7:1-10

Winau F, Hegasy G, Weiskirchen R, Weber S, Cassan C, Sieling PA, Modlin RL, Liblau RS, Gressner AM, Kaufmann SH (2007) Ito cells are liver-resident antigen-presenting cells for activating $\mathrm{T}$ cell responses. Immunity 26:117-129

Yamaguchi H, Kurosawa Y, Hashimoto K (1998) Expanded genomic organization of conserved mammalian MHC class I-related genes, human MR1 and its murine ortholog. Biochem Biophys Res Commun 250:558-564

Yang Z, Wang C, Wang T, Bai J, Zhao Y, Liu X, Ma Q, Wu X, Guo Y, Ren L (2015) Analysis of the reptile CD1 genes: evolutionary implications. Immunogenetics 67:337-346

Zajonc DM, Elsliger MA, Teyton L, Wilson IA (2003) Crystal structure of CD1a in complex with a sulfatide self antigen at a resolution of 2.15 A. Nat Immunol 4:808-815 